\title{
Prediction of IPL Match Outcome Using Machine Learning Techniques
}

\author{
Srikantaiah K C ${ }^{1, *}$, Aryan Khetan ${ }^{1}$, Baibhav Kumar $^{1}$, Divy Tolani ${ }^{1}$, Harshal Patel ${ }^{1}$ \\ ${ }^{1}$ Department of CSE, SJB Institute of Technology, Affilated to Visveswaraya Technological University BGS Health \& \\ Education City, Bengaluru-560060, Karnataka, India \\ *Corresponding author. Email: srikantaiahkc@gmail.com,
}

\begin{abstract}
India's most popular sport is cricket and is played across all over the nation in different formats like T20, ODI, and Test The Indian Premier League (IPL) is a national cricketmatch where players are drawn from regional teams of India, National Team and also from international team. Many factors like live streaming, radio, TV broadcast made this league as popular among cricket fans. The prediction of the outcome of the IPL matches is very important for online traders and sponsors. We can predict the match between two teams based on various factors like team composition, batting and bowling averages of each player in the team, and the team's success in their previous matches, in addition to traditional factors such as toss, venue, and day-night, the probability of winning by batting first at a specified match venue against a specific team. In this paper, we have proposed a model for predicting outcome of the IPL matches using Machine learning Algorithms namely SVM, Random Forest Classifier (RFC), Logistic Regression and K-Nearest Neighbor. Experimental results showed that the Random Forest algorithm outperforms other algorithms with an accuracy of $88.10 \%$
\end{abstract}

Keywords: Cricket, Indian Premier League, Logistic Regression, Machine Learning, Prediction of match outcome, Random Forest Classifier.

\section{INTRODUCTION}

Cricket is an outdoor game which is played by bat and bowl which includes 2 teams of 11 players each. Cricket is a teamwork game and is played mostly in three formats and occupies the 2 spots in the list of the most popular sport around the World. Like in any sport, there are many factors that plays an importantrole in deciding the winner of the match. Selection of a team is based on the player performance and other considerations like pitch factor, team size, venue etc. There are many variables and constraints which makes The Analysis of Cricket Match Difficult. There are three different formats of Cricket namely - Tests, Twenty-twenty (T20) and One Day International (ODI). Cricket is not only a nation game but also an international game. In this game, every ball is crucial because every ball can change the whole match in Cricket $[15,16]$.

Indian Premier League (IPL) is a national cricketmatch where players are drawn from regional teams of India, National Team and also from international team. It is based on 20-20 format and is owned by Celebrities, Businessmen and others and the entire IPL is controlled by Board of Control for Cricket in India (BCCI). For the current year (2021)there are total of 8 Teams in IPL namely, Royal Challengers Bangalore (RCB), Rajasthan Royals (RR), Chennai Super Kings (CSK), Mumbai Indians (MI), Kolkata Knight Riders (KKR), Delhi Capitals (DC), Punjab Kings (PK) and SunRisers Hyderabad (SRH). The motivation behind this paper includes the answers to following questions: "What is the probability of winning the game at a particular venue based on decision to field/bat first on winning the toss?", "Most dismissals by a bowler in a match?", "Does Home Ground have any effect on the result of the game?

In this paper We are trying to find out the match winner of an IPL match based on the stadium they are choosing and the toss decision using machine learning techniques like SVM, Random Forest, Logistic Regression etc. Remainder of the paper is organized as follows: The section 2 is the literature survey, section 3 deals with the problem definition and the architecture. Section 4 deals with the experimental results. Section 5 talks about the conclusion. 


\section{LITERATURE SURVEY}

Ahmad et al. [1], predicted the emerging players from batsman as well as from the bowlers using machine learning techniques. Song et al. [2] predicted estimation of the location of a moving ball based on the value of the cricket sensor network. Roy et al. [3] predicted ranking system which is based on the social network factors and their evaluation in the form of composite distributed framework using Hadoop framework and MapReduce programming model is used for processing the data. Priyanka et al. [4], predicted the outcome of IPL-2020 based on the 2008-2019 IPL datasets using Data Mining Algorithms with an accuracy of $82.73 \%$.

Kansal et al. [5], predicted player evaluation in IPL based on the 2008-2019 datasets using Data Mining Technique. Data mining algorithms are used which gives evaluation using player statistics assessing a player's performance and determining his base price. They predicted about how to select a player in the IPL, based on every player's performance history using algorithms like decision tree, Naïve Bayes and Multilayer perceptron (MLP). MLP outperforms better than other algorithms. Agrawal et al. [6], used Support Vector Machine (SVM), CTree, and Naïve Baiyes classifiers with accuracies of $95.96 \%, 97.97 \%$ and $98.98 \%$ respectively, to predict the probability of the winner of the matches. Barot et al. [7], predicted the match outcome based on the toss and venue.

Kaluarachchi et al. [8], predicted match outcome using home ground, time of the match, match type, winning the toss and then batting first by using Naïve Bayes classifier. Passi et al. [9], predicted the performance of players based on the runs and the number of wickets. Both the type of problems is treated as classification problems where the list of runs, and list of wickets are classified in different ranges based on machine learning algorithms. The Random Forest algorithm outperforms better than other algorithms. Nigel Rodrigues et al. [10], predicted the value of the traits of the batsmen and the bowlers in the current match. This would help in selecting the players for the upcoming matches by using past performances of a player against a specific opposition team by using Multiple Random Forest Regression.

Wright [11], predicted the possible fixture for a cricket match based on the various venue, teams, number of holidays between each match in a fair and efficient manner. A metaheuristic procedure is used to progress from the basic solution to a complex final solution by a technique, Subcost-Guided Simulated Annealing (SGSA). Maduranga et al. [12], predicted the outcome of any cricket match by using data mining algorithms and provided solutions for the approach used by other authors. Shetty et al. [13], predicted the capabilities of each player depending on various factors like the ground, pitch type, opposition team and several others by using machine learning techniques. The model gave an accuracy of $76 \%, 67 \%$, and $96 \%$ for batsmen, bowlers, and all-rounders respectively by using Random Forest Algorithm. This model helped them to select the best players of the game and predict outcomes of the match [25-29].

\section{PROBLEM DEFINITION AND ARCHITECTURE}

\subsection{Problem Definition}

Given IPL datasets of past 9 years, the main objective of this paper is to predict the outcome of an IPL match between two teams based on the analysis of previously stored data using Machine Learning algorithms. The information will be analyzed and preprocessed. After preprocessing the data will be used to train different models in order to give the outcomes. We will analyze the various datasets and use key variables such as strike rate, bowler economy, etc. and feed it as input to an algorithm will help us get the probable outcome of a match [16-19].

\subsection{Architecture}

The figure 1 represents the architecture of the model which includes different components like datasets, split data, Training, Testing, Supervised Learning models and Result.

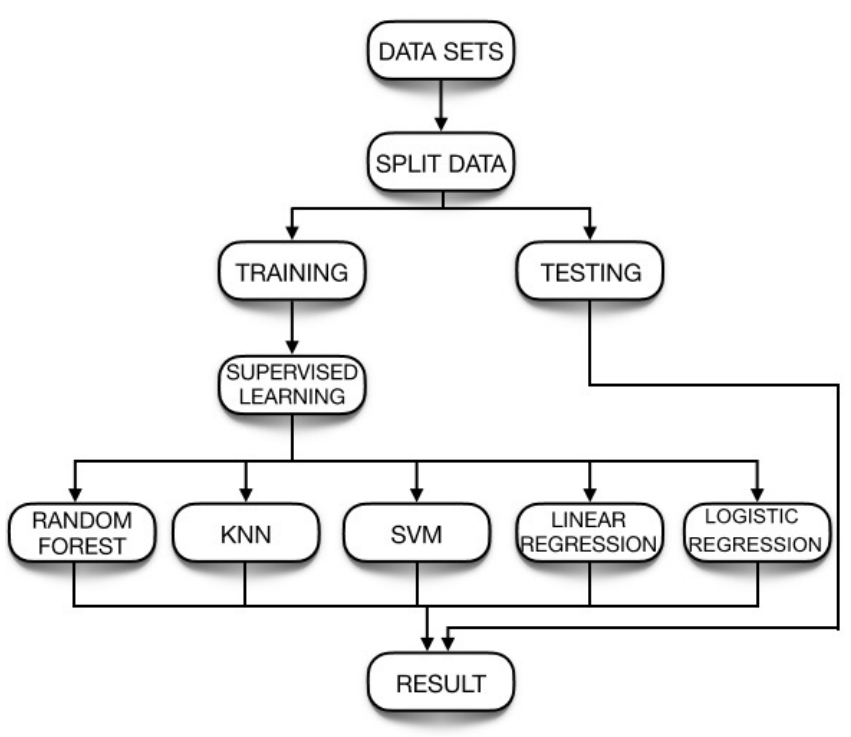

Figure 1 Architecture of the model

\subsubsection{Dataset}

The first step in the Architecture of model is to collect datasets from various sources. The data which is fed into the model decides how the model acts and reacts. If the data is accurate and up-to-date, then we will have accurate outcomes or predictions. So, we have collected 6 datasets from Kaggle.com which are as follows [20-21]. 


\subsubsection{Team wise home and away dataset}

The Teamwise Home and Away dataset contains 6 columns for the datasets which are as follows: home_wins, away_wins, home_matches, away_matches, home_win_percentage and away_win_percentage. It describes about the team performance in the home and away conditions with their win percentage. The table 1 shows the dataset and its description [22].

Table 1. Teamwise Home and Away dataset description

\begin{tabular}{|c|c|}
\hline Column name & $\begin{array}{l}\text { Column } \\
\text { description }\end{array}$ \\
\hline Home_wins & $\begin{array}{l}\text { Tells the number } \\
\text { of matches won by } \\
\text { a team in their } \\
\text { home ground. }\end{array}$ \\
\hline away_wins & $\begin{array}{l}\text { Tells the number } \\
\text { of matches won by } \\
\text { a team other than } \\
\text { their home ground. }\end{array}$ \\
\hline home_matches & $\begin{array}{l}\text { Tells the number } \\
\text { of matches played } \\
\text { by a team in their } \\
\text { home ground. }\end{array}$ \\
\hline Away_matches & $\begin{array}{l}\text { Tells the number } \\
\text { of matches played } \\
\text { by a team other } \\
\text { than their home } \\
\text { ground. }\end{array}$ \\
\hline home_win_percentage & $\begin{array}{l}\text { Percentage of } \\
\text { matches won when } \\
\text { played in home } \\
\text { ground. }\end{array}$ \\
\hline Away_win_percentage & $\begin{array}{l}\text { Percentage of } \\
\text { matches won when } \\
\text { played in ground } \\
\text { other than their } \\
\text { home ground. }\end{array}$ \\
\hline
\end{tabular}

\subsubsection{Matches dataset}

The Matches datasets contains 16 columns i.e season, city, date, team1, team2, toss_winer, toss_decision, result, dl_applied, winer, win_by_runs, win_by_matches and player_of_the_match, venue, umpire1 and umpire 2 . This dataset tells about the matches that are played between two teams and who was the winner of the match. It also tells about the toss decision taken in the match. The table 2 shows the dataset column and its description [23].

Table 2. Matches dataset description

\begin{tabular}{|l|l|}
\hline Column name & Column description \\
\hline Season & $\begin{array}{l}\text { This column tells the } \\
\text { season in which the } \\
\text { match was played. }\end{array}$ \\
\hline City & $\begin{array}{l}\text { The city in which the } \\
\text { match was played. }\end{array}$ \\
\hline Date & The date on which \\
\hline
\end{tabular}

\begin{tabular}{|c|c|}
\hline & $\begin{array}{l}\text { the match was } \\
\text { played. }\end{array}$ \\
\hline Team 1 & $\begin{array}{l}\text { Name of team who } \\
\text { played match. }\end{array}$ \\
\hline Team 2 & $\begin{array}{l}\text { Name of team which } \\
\text { played match. }\end{array}$ \\
\hline Toss winner & $\begin{array}{l}\text { Team that won the } \\
\text { toss. }\end{array}$ \\
\hline Toss decision & $\begin{array}{l}\text { Decision of batting } \\
\text { or fielding after } \\
\text { winning toss. }\end{array}$ \\
\hline Result & $\begin{array}{l}\text { Outcome of match } \\
\text { whether normal or } \\
\text { tie. }\end{array}$ \\
\hline Dl_applied & $\begin{array}{l}\text { Information on } \\
\text { whether DL method } \\
\text { was applied or not. }\end{array}$ \\
\hline Winner & $\begin{array}{l}\text { Team that won the } \\
\text { match. }\end{array}$ \\
\hline Win by runs & $\begin{array}{l}\text { The number of runs } \\
\text { by which the team } \\
\text { won. }\end{array}$ \\
\hline Win by wickets & $\begin{array}{l}\text { The number of } \\
\text { wickets by which the } \\
\text { team won. }\end{array}$ \\
\hline Player of match & $\begin{array}{l}\text { Name of player who } \\
\text { was awarded player } \\
\text { of the match. }\end{array}$ \\
\hline Venue & $\begin{array}{l}\text { Stadium in which } \\
\text { match took place. }\end{array}$ \\
\hline Umpire 1 & $\begin{array}{l}\text { On field umpire } \\
\text { name. }\end{array}$ \\
\hline Umpire 2 & $\begin{array}{l}\text { On field umpire } \\
\text { name. }\end{array}$ \\
\hline
\end{tabular}

\subsubsection{Player's dataset}

The Player's dataset contains 5 columns namely Player_Name, DOB, Batting_Hand, Bowling_Skill and Country. This dataset tells about the player and his bowling and batting style. The table 3 shows the dataset column and its description.

Table 3. Player's dataset description

\begin{tabular}{|l|l|}
\hline $\begin{array}{l}\text { Column name } \\
\text { Player Name }\end{array}$ & Column description \\
\hline DOB & Dame of the players \\
\hline Batting Hand & $\begin{array}{l}\text { Tells whether the players are left-handed } \\
\text { or right-handed. }\end{array}$ \\
\hline Bowling skill & Bowling style of players \\
\hline Country & Name of countries to which the player \\
& belongs. \\
\hline
\end{tabular}




\subsubsection{Teams Datasets}

The teams' datasets contain a single column named as team1 which shows the various IPL teams. The table 4 shows the dataset column and its description.

Table 4. Teams dataset description

\begin{tabular}{|l|l|}
\hline Column Name & Column Description \\
\hline Team & $\begin{array}{l}\text { Names of teams participating } \\
\text { in the IPL tournament. }\end{array}$ \\
\hline
\end{tabular}

\subsubsection{Deliveries dataset}

The Deliveries dataset contains 20 columns i.e innings, batting_team, bowling_team, over, Ball, Batsmen, Non_striker, Bowler, is_super_over, wide run, bye_run, Legbye_run, no_ball_run, penalty_run, batsmen_run, extra_runs, total_runs, players_dismissed, dismissal_kind, fielder. The table 5 shows the dataset column and its description [24].

Table 5. Deliveries dataset description

\begin{tabular}{|l|l|}
\hline Column Name & Column Description \\
\hline Inning & Tells us the inning being played \\
\hline Batting_team & $\begin{array}{l}\text { Tells us name of then batting } \\
\text { team }\end{array}$ \\
\hline Bowling_team & Tells name of bowling team \\
\hline Over & $\begin{array}{l}\text { Tells the over number being } \\
\text { bowled }\end{array}$ \\
\hline Ball & Tells the ball number of the over \\
\hline Batsmen & Name of batsmen on strike \\
\hline Non-striker & Name of batsmen on runner end \\
\hline Bowler & Name of bowler bowling \\
\hline Is_super_over & Tells if over is super over or not \\
\hline wide_run & $\begin{array}{l}\text { If there are runs given for wide } \\
\text { ball }\end{array}$ \\
\hline bentra_runs & If there are any bye runs given \\
\hline bye_run & If there are any leggy runs given \\
\hline If the ball was a no ball
\end{tabular}

\begin{tabular}{|l|l|}
\hline player_dismissed & If the player was given out or not \\
\hline dismissal_kind & What kind of dismissal it was \\
\hline Fielder & Player who caused dismissal \\
\hline
\end{tabular}

\subsubsection{Most_runs_average_strikerate dataset}

The Most_runs_average_strikerate dataset contains 6 columns namely batsman, total_runs, out, numberofballs, average, strikerate. This tells about player batting statistics. The table 6 shows the dataset column and its description.

Table 6. Most_runs_average_strikerate dataset description

\begin{tabular}{|l|l|}
\hline Column name & Column description \\
\hline Batsman & Name of the batsman. \\
\hline Total_runs & $\begin{array}{l}\text { Total runs scored by the } \\
\text { batsman }\end{array}$ \\
\hline Out & $\begin{array}{l}\text { Tells about the number of } \\
\text { times the batsman got out in } \\
\text { the entire IPL career. }\end{array}$ \\
\hline No_of_balls & $\begin{array}{l}\text { Number of balls faced by the } \\
\text { batsman overall. }\end{array}$ \\
\hline Average & $\begin{array}{l}\text { The average runs of the } \\
\text { batsman }\end{array}$ \\
\hline Strikerate & $\begin{array}{l}\text { Tells us about the strike rate } \\
\text { of the batsman. }\end{array}$ \\
\hline
\end{tabular}

\subsubsection{Split Data}

In this step the dataset is splitted into two groups, one for testing and one for training. The training data is used to train the Machine learning algorithms using supervised learning techniques. The trained model is then tested using the algorithms and the result is predicted. The testing data and training data are divided in the ratio 30:70.

\subsubsection{Training the model}

Training is the most important stage in Machine Learning. In this step the model is trained using training data to find patterns and make predictions. It results in the model learning from the dataset so that it can accomplish the given task.

\subsubsection{Testing the model}

After training the model, the performance of the model is checked. This is done by testing the model with previously unseen datasets. The unseen Datasets is called 
the testing datasets. So, in this step the model is tested by providing the unseen testing data.

\subsubsection{Supervised Learning}

There are different types of Supervised Machine Learning Techniques like Logistic Regression, Support Vector Machine, K-Nearest Neighbor, Random Forest classifier, linear Regression etc.

\section{EXPERIMENTAL RESULTS}

\subsection{Experimental Setup}

The Experiments were carried out on minimum Hardware requirements that include Processor of Intel Atom or Intel core i3, Disk space should be at least 1GB, Operating System must be windows 7 or later, macOS and Linux. The machine learning algorithm was implemented using Python 3.8 and Jupyter Notebook. The Datasets were downloaded from Kaggle.

\subsection{Analysis of IPL datasets}

The IPL dataset was analyzed, and some features were extracted out such as team winning percentage while batting first and team winning percentage while bowling first which is shown in figure 2 and figure 3 .

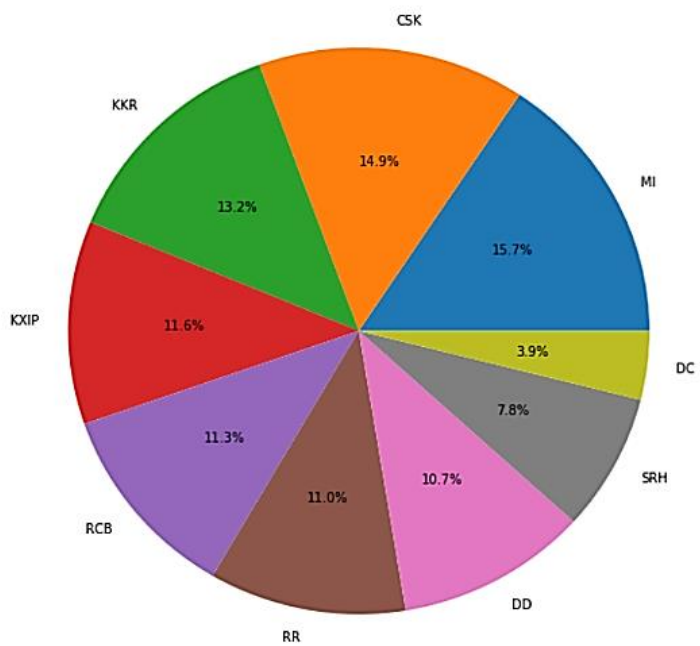

Figure 2 Team winning percentage while batting first

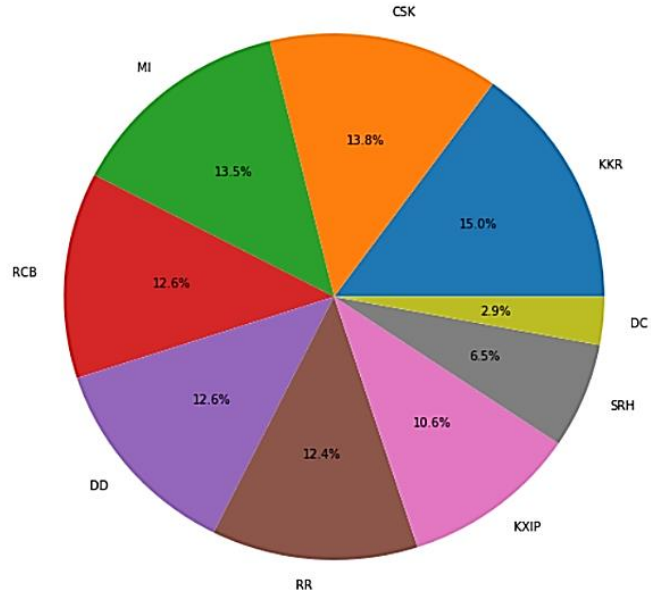

Figure 3 Team winning percentage while bowling first

Away win percentage is also being displayed in figure 4 below. From the figure 4, it can be seen that GL has the highest away win percentage.

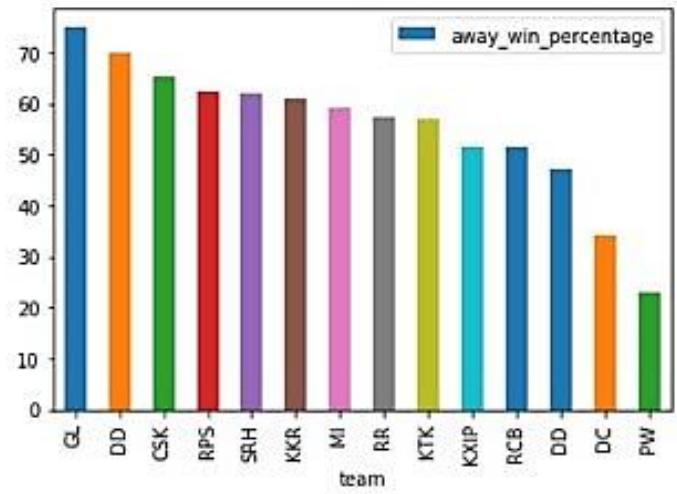

Figure 4 Teamwise winning percentage in away matches

Home win percentage is also being displayed in fig 5 below. From the fig 5, it can be seen that RPS has the highest home win percentage.

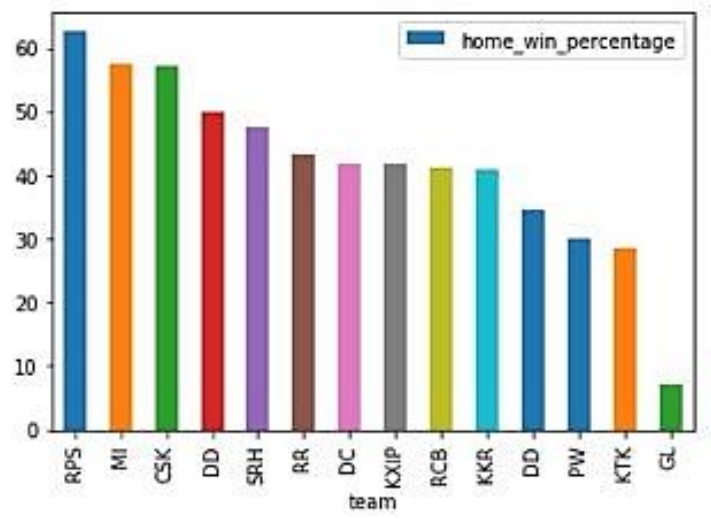

Figure 5 Teamwise winning percentage in home matches 
The fig 6 gives the information about how many times a particular team has won the toss and a pie chart is made from the dataset information depicting the winning percentage of both batting first and batting second at a particular venue after winning the toss in fig 7.

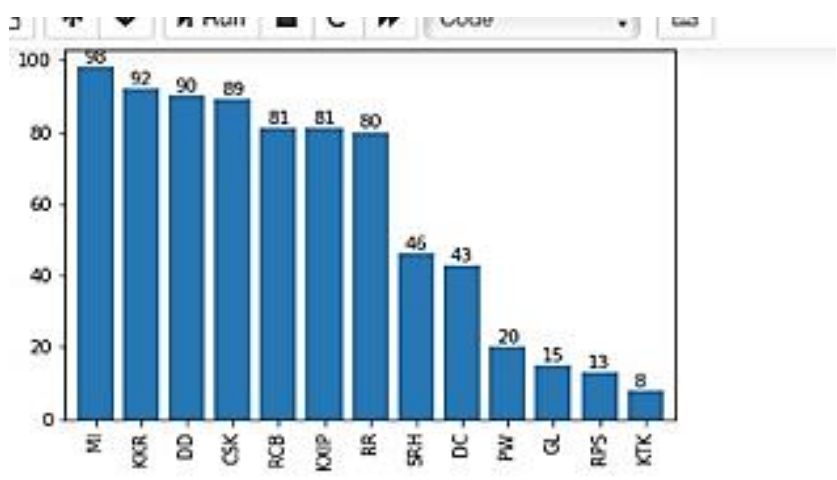

Figure 6 how many times a particular team won the toss

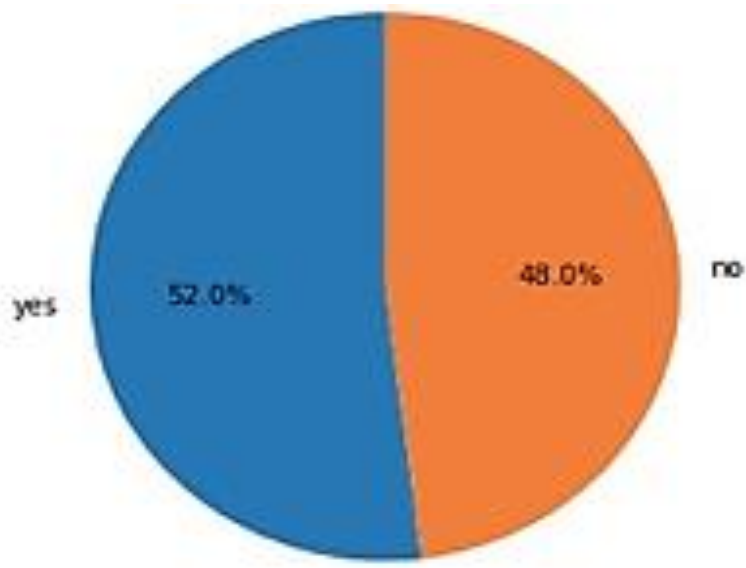

Figure 7 Winning percentage after winning the toss

The comparison between the two particular teams playing the match is shown through graph which could help in predicting the winner. Comparison between MI and CSK over various seasons is shown over here through figure 8 .

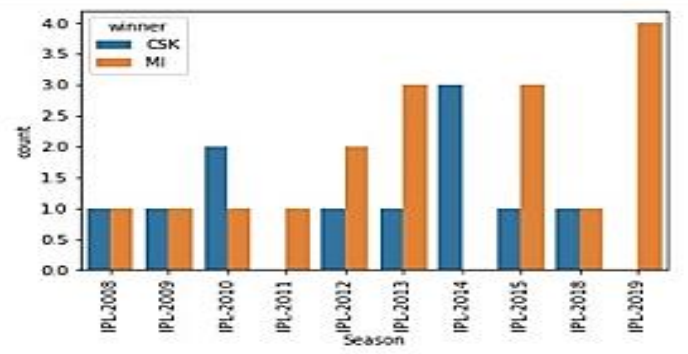

Figure 8 Team Comparison

Figure 9 displays the highest run scorers of IPL. From the fig, it can be seen that Virat Kohli is the highest run scorer with 5434 runs.

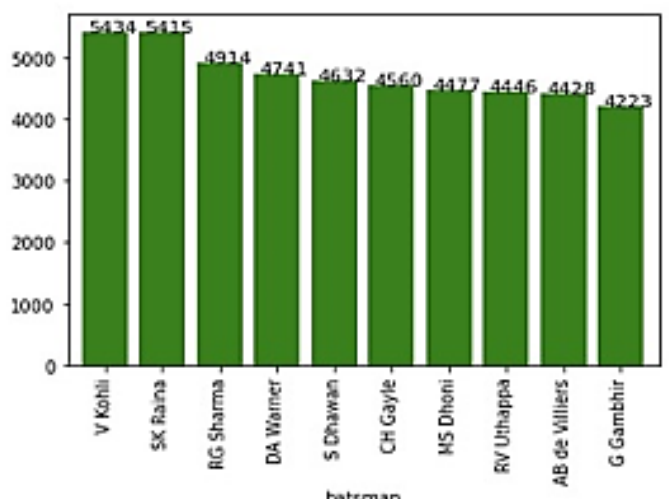

Figure 9 Top run scorers

\subsection{Performance Evaluation}

1) Accuracy: The fraction of correct forecast in all predictions is known as accuracy. In this experiment, random forest classifier outruns all the algorithms by predicting the result with highest accuracy of $88.10 \%$. The figure 10 shows the accuracies of the various algorithms implemented.

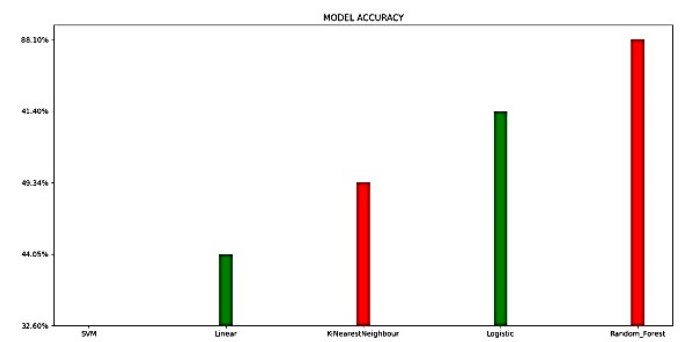

Figure 10 Accuracy of various algorithms

Table 7 shows about the various algorithms and their accuracies obtained. It is clear from the table that the random forest classifier performed better than other algorithm.

Table 7. Accuracy achieved by the algorithms

\begin{tabular}{|l|l|}
\hline Algorithm & Accuracy \\
\hline Random Forest & $88.10 \%$ \\
\hline K-Nearest Neighbor & $49.34 \%$ \\
\hline Logistic Regression & $51.40 \%$ \\
\hline SVM & $32.6 \%$ \\
\hline Linear Regression & $44.05 \%$ \\
\hline
\end{tabular}

Furthermore, 2-fold, 5-fold, 10-fold cross validation for rfc is also implemented for having better insights in table 8 
Table 8. Cross validation Technique

\begin{tabular}{|c|c|c|c|}
\hline NO. OF FOLDS & TRANSET & TEST SET & ACCURACY \\
\hline FOLD1 & 680 & 76 & $50.0 \%$ \\
\hline Fol.02 & 680 & 76 & $47 \%$ \\
\hline Fol. 3 & 680 & 76 & $51 \%$ \\
\hline Fol.104 & 680 & 76 & $58 \%$ \\
\hline Fol. 5 & 680 & 76 & $46 \%$ \\
\hline FOLDG & 680 & 76 & $49 \%$ \\
\hline Fold 7 & 681 & 75 & $55 \%$ \\
\hline Fo.108 & 681 & 75 & $43 \%$ \\
\hline Fold9 & 681 & 75 & $47 \%$ \\
\hline FOLD 10 & 681 & 75 & $53 \%$ \\
\hline
\end{tabular}

\section{CONCLUSIONS}

Predicting a winner in a sport such as cricket is especially challenging and involves very complex processes. But with the introduction of machine learning, this can be made much easier and simpler. In this paper, various factors have been identified that contribute to the results of the Indian Premier League matches. Factors that have a major impact on the outcome of an IPL match include the teams playing, the venue, the city, the toss winner and the toss decision. We have analyzed IPL data sets and predicted game results based on player performance. The methods used in the work to obtain the final test are Logistic regression, Support Vector Machine (SVM), Decision tree, Random Forest classifier and K-nearest neighborhood. Random Forest classification (RFC) outperforms the other algorithm.

As for the scope of the future, the focus can be on each player's performance and evaluate that on a regular basis for the season. His ratings for bowling and batting can also be predicted. There can be a chance to predict the man of the match for the two teams.

\section{ACKNOWLEDGMENTS}

We would like to express our sincere thanks to the Department of CSE, SJBIT for giving us a chance to work on this paper and our institution, SJB Institute of Technology for providing immense support throughout the paper. We would also like to extend our thanks to Visvesvaraya Technological University for providing us the opportunity to work on this paper.

\section{REFERENCES}

[1] Haseeb Ahmad, Ali Daud, Licheng Wang, Haibo Hong, Hussain Dawood and Yixian Yang, Prediction of Rising Stars in the Game of Cricket, IEEE Access, Volume 5, PP. 4104 - 4124, 14 March 2017.

[2] Haryong Song, Vladimir Shin and Moongu Jeon, Mobile Node Localization Using Fusion Prediction-Based Interacting Multiple Model in
Cricket Sensor Network, IEEE Transactions on Industrial Electronics, Volume: 59, Issue: 11, November 2012.

[3] Sarbani Roy, Paramita Dey and Debajyoti Kundu, Social Network Analysis of Cricket Community Using a Composite Distributed Framework: From Implementation Viewpoint, IEEE Transactions on Computational Social Systems, Volume: 5, Issue: 1, PP. 64-81, March 2018.

[4] Priyanka S, Vysali K, K B PriyaIyer, Score Prediction of Indian Premier League- IPL 2020 using Data Mining Algorithms, International Journal for Research in Applied Science \& Engineering Technology (IJRASET), Volume 8, Issue II, PP. 790-795.

[5] Prince Kansal, Pankaj Kumar, Himanshu Arya, Aditya Methaila, Player valuation in Indian premier league auction using data mining technique, International Conference on Contemporary Computing and Informatics (IC3I), 27-29 Nov 2014

[6] Shilpi Agrawal, Suraj Pal Singh, Jayash Kumar Sharma, predicting results of IPL T-20 Match using Machine Learning, 2018 8th International Conference on Communication Systems and Network Technologies (CSNT), 24-26 Nov. 2018.

[7] Harshit Barot, Arya Kothari, Pramod Bide, Bhavya Ahir, Romit Kankaria, Analysis and Prediction of Indian Premier League, 2020 International Conference for Emerging Technology (INCET), 5-7 June 2020.

[8] Amal Kaluarachchi, S. Varde Aparna, CricAI: A classification-based tool to predict the outcome in ODI cricket, 2010 Fifth International Conference on Information and Automation for Sustainability, 17-19 Dec. 2010.

[9] Kalpdrum Passi and Nirav Kumar Pandey, predicting player's performance in one day international cricket matches using machine learning, Volume 8, Computer Science \& Information Technology, 2018.

[10] Nigel Rodrigues, Nelson Sequeira, Stephen Rodrigues, Varsha Shrivastava, Cricket Squad Analysis Using Multiple Random Forest Regression, IEEE Xplore, 1st International Conference on Advances in Information Technology, 2019.

[11] M. B. Wright, Scheduling fixtures for New Zealand Cricket, IMA Journal of Management Mathematics 16, PP. 99-112, 2005.

[12] Manuka Maduranga, Hatharasinghe, Guhanathan Poravi, Data Mining and Machine Learning in Cricket Match Outcome Prediction: Missing Links, 5th International Conference for Convergence in Technology (I2CT), Mar 2931, 2019.

[13] Monali Shetty, Sankalp Rane, Chaitanya Pandita, Suyash Salvi, Machine learning-based 
Selection of Optimal sports Team based on the Players Performance, Proceedings of the Fifth International Conference on Communication and Electronics Systems (ICCES 2020), IEEE Conference Record, ISBN: 978-1-7281-5371-1, 2020.

[14] Balasundaram A, Ashokkkumar S, Jayashree D, Magesh Kumar S, Data Mining based Classification of Players in Game of Cricket, proceedings of the International Conference on Smart Electronics and Communication (ICOSEC 2020), IEEE Xplore Part Number: CFP20V90-ART; ISBN: 978-1-7281-5461-9.

[15] Jalaz Kumar, Rajeev Kumar, Pushpender Kumar, Outcome Prediction of ODI Cricket Matches Using Decision Trees and MLP Networks, 2018 First International Conference on Secure Cyber Computing and Communication (ICSCCC).

[16] Prabu, S., Balamurugan Velan, F. V. Jayasudha, P. Visu, and K. Janarthanan. "Mobile technologies for contact tracing and prevention of COVID-19 positive cases: a cross-sectional study." International Journal of Pervasive Computing and Communications (2020).

[17] Subramani, Prabu, K. Srinivas, R. Sujatha, and B. D. Parameshachari. "Prediction of muscular paralysis disease based on hybrid feature extraction with machine learning technique for COVID-19 and post-COVID-19 patients." Personal and Ubiquitous Computing (2021): 1-14.

[18] Do, Dinh-Thuan, Tu Anh Le, Tu N. Nguyen, Xingwang Li, and Khaled M. Rabie. "Joint impacts of imperfect CSI and imperfect SIC in cognitive radio-assisted NOMA-V2X communications." IEEE Access 8 (2020): 128629-128645.

[19] Le, Ngoc Tuyen, Jing-Wein Wang, Duc Huy Le, Chih-Chiang Wang, and $\mathrm{Tu}$ N. Nguyen. "Fingerprint enhancement based on tensor of wavelet subbands for classification." IEEE Access 8 (2020): 6602-6615.

[20] Nguyen, Tu N., Bing-Hong Liu, Nam P. Nguyen, and Jung-Te Chou. "Cyber security of smart grid: attacks and defenses." In ICC 2020-2020 IEEE International Conference on Communications (ICC), pp. 1-6. IEEE, 2020.

[21] Kumar, M. Keerthi, B. D. Parameshachari, S. Prabu, and Silvia liberata Ullo. "Comparative Analysis to Identify Efficient Technique for Interfacing BCI System." In IOP Conference Series: Materials Science and Engineering, vol. 925, no. 1, p. 012062. IOP Publishing, 2020

[22] Rajendran, Ganesh B., Uma M. Kumarasamy, Chiara Zarro, Parameshachari B. Divakarachari, and Silvia L. Ullo. "Land-use and land-cover classification using a human group-based particle swarm optimization algorithm with an LSTM Classifier on hybrid pre-processing remote- sensing images." Remote Sensing 12, no. 24 (2020): 4135.

[23] Puttamadappa, C., and B. D. Parameshachari. "Demand side management of small scale loads in a smart grid using glow-worm swarm optimization technique." Microprocessors and Microsystems 71 (2019): 102886.

[24] K. Yu, L. Tan, X. Shang, J. Huang, G. Srivastava and P. Chatterjee, "Efficient and PrivacyPreserving Medical Research Support Platform Against COVID-19: A Blockchain-Based Approach", IEEE Consumer Electronics Magazine, doi: 10.1109/MCE.2020.3035520.

[25] K. Yu, M. Arifuzzaman, Z. Wen, D. Zhang and T. Sato, "A Key Management Scheme for Secure Communications of Information Centric Advanced Metering Infrastructure in Smart Grid," IEEE Transactions on Instrumentation and Measurement, vol. 64, no. 8, pp. 2072-2085, August 2015.

https://ieeexplore.ieee.org/document/7138617

[26] K. Yu, L. Lin, M. Alazab, L. Tan, B. Gu, "Deep Learning-Based Traffic Safety Solution for a Mixture of Autonomous and Manual Vehicles in a 5G-Enabled Intelligent Transportation System", IEEE Transactions on Intelligent Transportation Systems, doi: 10.1109/TITS.2020.3042504.

[27] K. Yu, L. Tan, M. Aloqaily, H. Yang, and Y. Jararweh, "Blockchain-Enhanced Data Sharing with Traceable and Direct Revocation in IIoT", IEEE Transactions on Industrial Informatics, doi: 10.1109/TII.2021.3049141.

[28] Z. Guo, K. Yu, Y. Li, G. Srivastava, and J. C. W. Lin, "Deep Learning-Embedded Social Internet of Things for Ambiguity-Aware Social Recommendations", IEEE Transactions on Network Science and Engineering, doi: 10.1109/TNSE.2021.3049262.

[29] Z. Guo, A. K. Bashir, K. Yu, J. C. Lin, Y. Shen, "Graph Embedding-based Intelligent Industrial Decision for Complex Sewage Treatment Processes", International Journal of Intelligent Systems, 2021, doi: 10.1002/int.22540. 